\title{
PARAMEDICS' SAFETY DURING TRANSPORTATION OF THE PATIENT UNDER ONGOING NEBULIZATION IN THE CONTEXT OF COVID-19 OUTBREAK
}

\author{
Tomasz Klosiewicz ${ }^{1,2}{ }^{\oplus}$, Piotr Ziemak $^{3} \odot$, Radoslaw Zalewski ${ }^{1} \oplus$, Norbert Tobola ${ }^{3}{ }^{\circ}$, \\ Maciej Antoszczuk ${ }^{3}$, Mateusz Puslecki ${ }^{1,4}$ \\ ${ }^{1}$ Department of Medical Rescue, Poznan University of Medical Sciences, Poznan, Poland \\ ${ }^{2}$ Polish Society of Medical Simulation, Poland \\ ${ }^{3}$ Center of Medical Simulation, Poznan University of Medical Sciences, Poznan, Poland \\ ${ }^{4}$ Department of Cardiac Surgery and Transplantology, Poznan University of Medical Sciences, Poznan, Poland
}

KEY WORDS: COVID-19, SARS-CoV-2, nebulization treatment, ambulance, nebulizers, occupational safety

Disaster Emerg Med J 2020; 5(4)

\section{Dear Editor,}

a novel coronavirus (COVID-19) is associated with human-to-human transmission. The ongoing outbreak of COVID-19 has spread rapidly and sparked global concern. Healthcare workers are highly exposed to the infection because of aerosol possible transmission [1]. Prehospital clinicians should pay particular caution if an aerosol-generating procedure, such as a bag valve mask ventilation, suctioning, endotracheal intubation, nebulizer treatment or resuscitation is being provided [2].

Heinzerling et al. have proved that $67 \%$ of medical personnel who assisted COVID-19-infected patients undergoing nebulization, have developed infection themselves. It is important to mention that the virus has spread within hospital environment. Therefore, it can be assumed that in a limited space of an ambulance chances of getting an infection are significantly higher [3].

Nebulizer therapy is the basis for the treatment of patients with asthma or COPD exacerbation. In such patients, the administration of betasympathomimetic, cholinolytics and steroids in nebulization is a standard procedure. Unfortunately, some patients infected with COVID-19 remain asymptomatic and may be the source of infection. In a specific group of patients, nebulization may be postponed until a patient is admitted to the emergency department.
This group includes patients whose epidemiological history indicates a high risk of COVID-19 infection and who do not present signs of respiratory failure. However, there remains a group of patients who do not show signs of infection but suffer from an asthma attack.

The authors intended to estimate the possibility of paramedic's exposure to the aerosol generated during nebulization inside an ambulance medical compartment. The authors made a self-designed system, simulating the patient's expiration and nebulization procedure was simulated. Nebulization mask was applied to the face of ResusciAnne mannequin. On the other side of the face, the face mask was tightly fixed and connected to the ventilator (Weinmann Medumat Standard, Weinmann Emergency Medical Technology GmbH, Hamburg, Germany). The settings of the ventilator were as follows: ventilation rate $12 / \mathrm{min}$, minute ventilation $10 \mathrm{l} / \mathrm{min}$, maximum pressure $20 \mathrm{mbar}$. The UV-marker solution was poured into the nebulizer tank (FluoAdd, B. Braun Medical AG, Sempach, Switzerland). The oxygen flow to nebulizer was set to $61 / \mathrm{min}$ a procedure was carried out during 10 minutes. Figure 1 and 2 illustrate how a nebulizer aerosol reaches a paramedic's seat.

The most frequent treatment introduced by paramedics for patients with dyspnea is nebulization, 


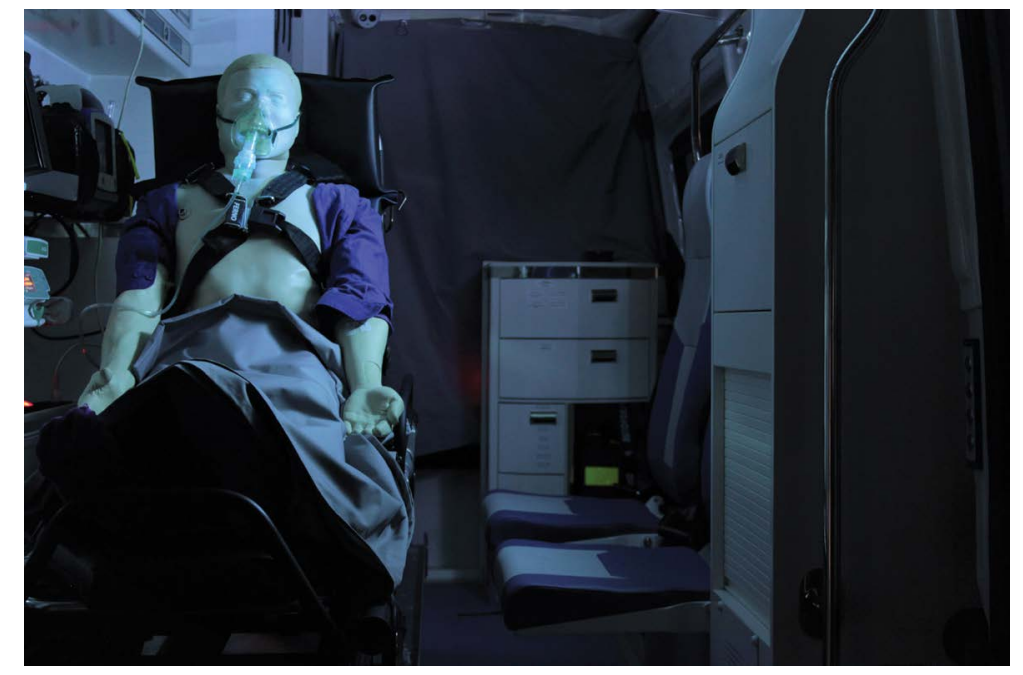

FIGURE 1. The space without aerosol

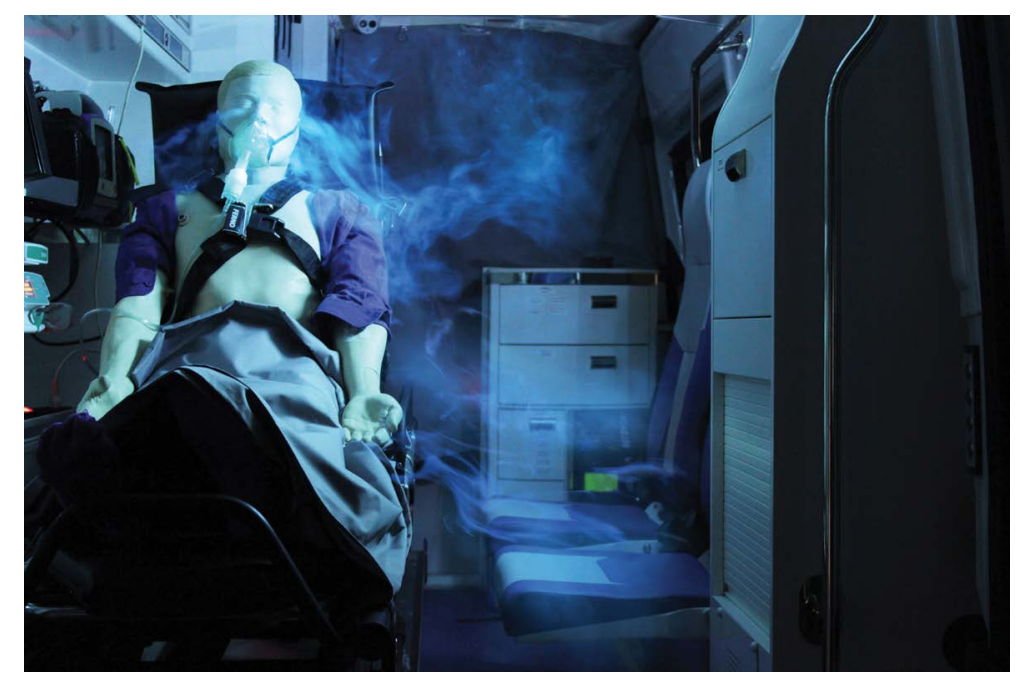

FIGURE 2. Aerosol coverage around paramedic's seat

which results in producing large amounts of aerosol that enables easier transmission of infectious pathogens, including COVID-19. Postpone the treatment for patients with clear indications for nebulization is against the proper guidelines [4]. The additional research has proved that ambulance ventilation turning on the system does not have influence on decreasing the risk of aerosol spread for paramedics. Aerosol exposures were not significantly different at various locations within the compartment, including locations behind and beside the patient [5].

The results of the research are disconcerting for paramedics. Patients showing no symptoms of COVID-19, but having indications for nebulization, remain a considerable danger for paramedics. The authors see the need to implement proper, ambu- lance dedicated tools, including personal protective equipment for safe procedures during transportation.

\section{REFERENCES}

1. van Doremalen N, Bushmaker T, Morris DH, et al. Aerosol and Surface Stability of SARS-CoV-2 as Compared with SARS-CoV-1. N Engl J Med. 2020; 382(16): 1564-1567, doi: 10.1056/NEJMc2004973, indexed in Pubmed: 32182409.

2. Ruetzler K, Smereka J, Ludwin K, et al. Respiratory protection among healthcare workers during cardiopulmonary resuscitation in COVID-19 patients. Am J Emerg Med. 2020 [Epub ahead of print], doi: 10.1016/j. ajem.2020.05.014, indexed in Pubmed: 32444293.

3. Heinzerling A, Stuckey MJ, Scheuer T, et al. Transmission of COVID-19 to Health Care Personnel During Exposures to a Hospitalized Patient - Solano County, California, February 2020. MMWR Morb Mortal 
Wkly Rep. 2020; 69(15): 472-476, doi: 10.15585/mmwr.mm6915e5, indexed in Pubmed: 32298249.

4. Andrew $E$, Nehme Z, Bernard $S$, et al. 6 Characteristics of thunderstorm asthma EMS attendances in Victoria, Australia. BMJ Open. ; 2017: 7, doi: 10.1136/bmjopen-2017-EMSabstracts.6.
5. Lindsley WG, Blachere FM, McClelland TL, et al. Efficacy of an ambulance ventilation system in reducing EMS worker exposure to airborne particles from a patient cough aerosol simulator. J Occup Environ Hyg. 2019; 16(12): 804-816, doi: 10.1080/15459624.2019.1674858, indexed in Pubmed: 31638865. 